\title{
Study on the Relationship between Cinema Language and Sound Image
}

\author{
Di Liu \\ Foreign Languages Studies \\ Anshan Normal University \\ Anshan, Liaoning Province, China
}

\author{
Suyan Zhang \\ Foreign Languages Studies \\ Anshan Normal University \\ Anshan, Liaoning Province, China
}

\begin{abstract}
This paper commences with some introductory points on the relationship between cinema language and sound image. It highlights arguments put forward by film-music scholars and theoreticians such as Claudia Gorbman, Kathryn Kalinak, Sergei M. Eisenstein, Paul Willemen and Wlad Goldizh in particular. This paper also engages with these various perspectives in order to both assess their claims and outline the resultant debates on the relationship between music and image in cinema in general.
\end{abstract}

Keywords - cinema language; sound image; the relationship between music and image

\section{INTRODUCTION}

This paper will commence with some introductory points on the relationship between music and cinema. In order to offer a better understanding of the use of music in cinema, this paper will highlight arguments put forward by filmmusic scholars and theoreticians such as Claudia Gorbman, Kathryn Kalinak, Sergei M. Eisenstein, Paul Willemen and Wlad Goldizh in particular. I will engage with these various perspectives in order to both assess their claims and outline the resultant debates on the relationship between music and image in cinema in general.

\section{KATHRYN KALINAK: A GENERAL REVIEW OF MUSIC AND IMAGE RELATIONSHIP}

In Fred Karlin and Rayburn Wright's book, On the Track: A Guide to Contemporary Film Scoring (1990), Craig Safan (a contemporary film composer) explains the relationship between music and image in these terms: "You excite an audience in a certain way and if you betray them they won't want to see your movie. And musically, you can betray your audience. You have to be very careful about that" (Safan, 1990; cited in Karlin \& Wright, 1990: 127). From Safan's explanation, it becomes clear that film music obviously does not exist in an empty space; it shares the screen with the image and other elements of the soundtrack.

In her article "The Language of Music: A Brief Analysis of Vertigo"(2003), Kathryn Kalinak demonstrates how setting can be evoked to be "perfectly innocuous": ... an eighteenth-century drawing room where two lovers are reunited after numerous narrative complications. But instead of a soaring melody played by an off-screen orchestra, we hear tremolo strings and dissonant chords. Our tendency as spectators would be to perceive that music as meaningful, specifically to read the scene as suspenseful. We might be expecting some kind of narrative complication or even a visual shock because of the music. If these expectations are thwarted, most spectators would feel manipulated, even cheated (Kalinak, 2003: 21).

Kalinak analyzes how the music for the theme of Vertigo plays out against a series of "brightly coloured geometric spirals which spin against a black background" (Kalinak, 2003: 21). She emphasizes how it is important to note the relationship between these images and music because the quality of the music is reflected in the images presented; and in the way that the distinctive musical passage is repeated (and varied) throughout a musical text in such a way that it is almost waving uninterrupted from the beginning to the end. In Kalinak words, "it is the mesmerizing evocation of dizziness" (Kalinak, 2003: 22).

At this point I would suggest that the correspondence between the circularity of these films' images and the music themes is obvious. It shows that music and image collaborate in the filmic process. Film music thus owns the ability to shape depth perspectives of auditory and aesthetic perception. For this, Kalinak claims as follows:

Film music's power is derived largely from its ability to tap specific musical conventions that circulate throughout the culture. But that power is always dependent on a coexistence with the visual image, a relationship bounded by the limits of credibility itself (Kalinak, 2003: 22).

Therefore, it is necessary to consider the interaction between music and the filmic narratives and from these consider how this relationship can support a further musicimage drift from a mutual synaesthetic dependency in the cinematic illusion.

\section{SERGEI M. EISENSTEIN: A SYNAESTHETIC \\ RELATIONSHIP BETWEEN “PICTURE RHYTHM” AND "Musical MOVEMENT"}

Sergei M. Eisenstein was not only a filmmaking practitioner but also a major theorist. In a number of his writings and his discussions of synaesthesia, Eisenstein demonstrates how he sees and structures his films musically. Generally speaking, throughout Eisenstein's analyses of his own movies, he consciously represents musical terms such as 
polyphonic, contrapuntal, rhythmic and symphonic in order to highlight the ways in which different filmic strands might structurally interlock (Brown, 1994). For example, when he wrote his book The Film Sense between 1937 and 1944, Eisenstein had already constructed graphs and considered both the diagram of "picture rhythm" and the diagram of "musical movement" as the same movement (Prendergast, 1992: 236). To illustrate this point, Eisenstein states:

Now let us collate the two graphs, what do we find? Both graphs of movement correspond absolutely, that is, we find a complete correspondence between the movement of the music and the movement of the eye over the lines of the plastic composition. In other words, exactly the same motion lies at the base of both the musical and the plastic structures (Eisenstein \& Leyda, 1947: 23).

The film technique with which Eisenstein is most closely associated is "montage" which places seemingly incongruous elements next to each other, forcing us to evaluate new arrangements and to question our own learned senses of appropriate stylistic continuity (Brown, 1994: 27). With Eisenstein, there is a sense not only that he wishes to arouse a certain musicality within the silent image, but also that he has a deeply poetic ability to play sensorial evocations off one another. In other words, if we accept Eisenstein's claim of a correspondence between the music and the picture, then we can imagine that the musical development will match that of the image. The music then should demonstrate different meanings with close-ups and with wide shots within the film (Bordwell, 1992).

However, Eisenstein's ideas on the correspondence between picture and music are challenged by Roy A. Prendergast in his article 'The Aesthetics of Film Music' (1992). Prendergast argues that "in the plastic arts the concept of rhythm is largely metaphorical" and not as in Eisenstein's graphs “compounded” (Prendergast, 1992: 235).

Following this, Prendergast challenges the visual equation that Eisenstein makes through his adoption of a graphic system:

In reality, what the graph proves is that there is a similarity between the notation of the music and the picture sequence. This is an extremely important and crucial distinction upon which the whole of Eisenstein's premise rests. But Eisenstein's comparison is a bogus one, for musical notation is merely a graphic fixation of actual musical movement, "the static image of a dynamic phenomenon," according to Hanns Eisler. Music is an art that moves through time, an art that cannot be perceived instantaneously; whereas, in Eisenstein's graph, the pictures are perceived instantly. And while it is possible for the film director, through the composition of his shot, to control somewhat the direction of the viewer's eye movement across the frame, there is no way to control the rhythm or pace of that movement (Prendergast, 1992: 237).

Despite the critical attention given to film music by Eisenstein, the emphasis is still on the relationship between "picture rhythm" and "musical movement" (Prendergast, 1992: 236). Such approaches do not fully address the cultural context of national cinema. For instance, in his book Overtones and Undertones: Reading Film Music (1994), Royal S. Brown cites Eisenstein in support of his argument on the reasons why film and image blend together so well. Brown suggests that because of "the cinema's iconicity" and its "essentially prosaic realism", it "needed something to justify its very existence as an art form ... to escape from the trap of preferentiality in order to impose perception of its artistic structure and content" (Brown, 1994: 19-20). However, Brown's notion of the iconic nature of cinema assumes a universalism that does not fully equate with the function of music in Chinese cinema as a historical development.

Interestingly, following Eisenstein and Brown's thinking, David Bordwell's 'Cinema/Sound' essay urges us to think of cinema more musically (Bordwell, 1992; cited in Altman, 1992). Eisenstein's concept of an "audiovisual score" is a result of an understanding of music for film theoreticians (Brown, 1994: 20).

\section{Claudia Gorbman: THE PaRALlel AND}

\section{COUNTERPOINT RELATIONSHIP BETWEEN MUSIC AND SCENE}

Eisenstein has pointed to music as one of the elements in a film segment: the corroboration causes meaning. In fact, image, sound effects, dialogue, and music are never separated from each other during the viewing experience, thus, they form a certain expression of combination (Evans, 1975). From this point of view, there are some possible narrative/music relationships discussed and argued by a number of film scholars and theoreticians that need to be considered. As I have noted before, Kathryn Kalinak claims that there is a synchronization of music and image, and Eisenstein demonstrates the synaesthetic relationship between picture rhythm and musical movement. Siegfried Kracauer writes that counterpoint occurs when music and picture convey "different meanings" that meet in a montage effect. He elaborated on this point: "Imagine the close up of a sleeping face which appears to the intriguing discrepancy between these sounds and so peaceful a picture should puzzle us" (Kracauer, 1974: 24, cited in Gorbman, 1987: 24). Claudia Gorbman agrees with Siegfried Kracauer's claim and she also reminds us that either the music "resembles" or it "contradicts" the action or mood of what happens on the screen (Gorbman, 1987: 14). Gorbman then further summarizes the concepts of the parallelism and the counterpoint relationship in between music and image (Gorbman, 1987).

Claudia Gorbman continues to argue that there is no other way to qualify film music that does not lie between these opposites of parallelism and counterpoint, but outside them. For Gorbman:

If we must summarize music-image and music-narrative relationships in two words or less, mutual implication is more accurate, especially with respect to films of any narrative complexity. The notions of parallel and counterpoint erroneously assume that the image is autonomous. Further, it is debatable that information conveyed by disparate media can justifiably be called same or different. Kracauer's very examples show how music 
helps the viewer to define the images, themselves polysemic (Gorbman, 1987: 15).

Therefore, to sum up, music is usually sufficient to accompany a segment of film.

Whatever music is applied to a film segment will do something; will have an effect-just as whatever two words one puts together will produce a meaning different from that of each word separately, because the reader/spectator automatically imposes meaning on such combinations (Gorbman, 1987: 16).

\section{BAZIN, GOLDICH AND WILlEMEN: CINEMA LANGUAGE AND SOUND IMAGE}

There are a few important innovations and debates around issues concerned with cinema language in general. The reason for reviewing them is that this context is necessary when we come to assess the development and innovation in Chinese cinema language. Moreover, the process through which old language is replaced by the new is quicker in cinema than in any other art. Therefore, this part of the review will signpost the main debates on cinema language among Andre Bazin, Wlad Godzich, and Paul Willemen.

One of the main innovations in contemporary cinematic language is the breakthrough in the use of shots, both in theory and in practice. The principle of montage invented by D. W. Griffith and Sergei Eisenstein has long been regarded as the basis of film art (Gray, 1967). The position of this aesthetic was so strong that it seemed immune to challenge. For decades, and even today, filmmakers not only have developed the use of montage but have also reached the point of abandoning it (Silbergeld, 1999).

Early in the 1950s, a group of film critics and directors led by French film critic, Andre Bazin began to challenge the montage theory (Katz, 1979). The theory they proposed was that of the "long take" (Bazin, Vol. I, 1958: 36). Bazin criticised Eisenstein's theory that took shots as primary materials into which montage alone could generate life and thus produce art. He pointed out that montage theory put too much emphasis on editing (Gray, 1967). Actually, Bazin argued a single shot in itself is a forceful representation that possesses the power of intense artistic compression. To Bazin, "if elements within the composition of shots are brought effectively into play, a film can be completely constructed of long takes" (Gray, 1967: 224). Of course this is not the only idea behind Bazin's aesthetics and theory. Bazin's theory influenced the art of world film enormously, especially when directors who applied the principles of the long take in their filmmaking appeared in a number of countries in the $1950 \mathrm{~s}$.

In The Evolution of the Language of Cinema (1958), Andre Bazin rejected the conventional antithesis of silent versus sound cinema. He proposed an alternative view based on two other "fundamentally different conceptions of cinematographic expression" (Bazin, Vol. I, 1958: 36) which both pre-dated and survived the coming of sound: "directors who believe in the image and those who believe in reality" (Gray, 1967: 225). Bazin argues that montage as a technique allows an impression of interpretation on events they portrayed. The effect of this, he claims, is to create a meaning not objectively present in the images but derived purely from their juxtaposition. This style was typified by the work of D. W. Griffith, Sergei M. Eisenstein and Alfred Hitchcock (Silbergeld, 1999). The film-image sound, in Bazin's view, should be evaluated "according not to what it adds to reality but to what it reveals of it" (Gray, 1967: 224).

Bazin was not only a theorist and aesthetician but also an extraordinarily perceptive critic. He fully appreciated the signifying operations of individual films (Katz, 1979). It is therefore understandable that he could offer so many interesting suggestions for the contradictions between his theoretical and critical work. Bazin argued that "the image should ideally produce an objective record of reality rather than the illusion of realism by means of a network of signs" (Bazin, 1958: 42). This perspective on the interpretation of realism places Bazin within a semiotic tradition in film analysis (Katz, 1979). However, in the Ontology of the Photographic Image (1958), Bazin develops in detail the argument that cinema is also a language. He noted that: "the perfect transparency was precluded by the current limitations of film technology and might indeed never be possible" (Bazin Vol.1, 1958: 44). This contradiction is again found in one of his favourite images for the relation between film and reality: "an asymptote, a curve which gradually approaches a straight line but which meets it only at infinity" (Bazin Vol.1, 1958: 44-52).

Another important tendency in the development of film language is the exploration of a new means of considering cinematic representations as plastic arts (Kaplan, 1993). There has long been debate on the difference between theatrical film and literary film.

Wlad Godzich demonstrates a similar claim in his book The Culture of Literacy (1994). Concerning the reading of oral literature in The Culture of Literacy, Paul Willemen contends that Godzich's arguments: "throw a different light on the apparently interruptive intrusions of the narratorial agency" (Willemen, 2002: 10). First of all, Willemen considers how Godzich conceptualises the movement from "pre-modern, indeed, pre-industrial oral cultures via the introduction of the book and print technology to written cultures" as one of transition (Willemen, 2002: 6). Willemen goes on to address the issue of Godzich's warning that oral cultures were not essentially more democratic than written cultures.

Willemen takes up Godzich's suggestion that "it might be better to talk of an auditive culture rather than an oral culture" (Godzich, 1994: 79), and concludes that this recognition "has far reaching implications for ways of approaching the extremely insistent and emphatic soundtrack in Turkish or Indian films", and even the use of sound and music in Hong Kong's or India's commercial cinema (Willemen, 2002:11).

In addition, Willemen highlights Godzich's claims of a relationship between the auditive culture and the modernist cinema: on the similarities between an auditive culture and some increasingly dominant aspects of contemporary 
industrial mass culture such as television, the music industry and advertising and he makes the extremely valuable observation that those who are not wholly subjugated by such manipulative strategies are not necessarily critical, modernised subjects, as is implied by the dominant modernist cinema (Willemen, 2002:11).

Generally speaking, no matter how the cinema's industrial development came about, both the auditive culture and oral culture have been a constant throughout the different periods. What Willemen and Godzich miss, is that a demonstrable relationship between auditive and oral cultures is to be found in cinema, particularly in the modernisation era.

In their book Cross-Cultural Filmmaking: A Handbook for Making Documentary and Ethnographic Films and Videos (1997), Ilse Barbash and Lucien Taylor point out that "zooming into a person can never convey the same sensation as moving closer to the person. [If you zoom] the move feels unnatural and your spectators will sense (and share) your distance from the action" (Barbash \& Taylor, 1997:114). Willemen claims that the zoom should be used cautiously in documentary work. He also looks at the zoom in a different context, as a marker whereby discourse acquires a different set of connotations (Willemen, 2002). Furthermore, Willemen points out that the zoom displays recognition within the filmic discourse, or implies recognition of presence for the audience (2002). Willemen, here, is characterising the use of zoom in the Euro-American zone, however, in this sense, it is very important and necessary to further understand and research the development of cinema as a new technology language in the twenty-first century.

\section{CONCLUSION}

Since a number of recent films present their content and artistic appeal through synthetic use of such aural and visual means as lighting, colour, performance, combinations of sound and image, and changes in rhythm, film can therefore become a visual symphony of art. Meanwhile, there are new cinematic techniques of presentation such as the microzoom, titled shots, and others that also continue to make fresh appearances. Consequently, sound film, which long explored the relationship between sound and image, has gradually illustrated the principles of the combination, opposition, and separation of the two, and has increased the expressive power of sound and image.

This paper has laid out the main arguments about the relationship between music and image. However, what is lacking in these generalised accounts of film music is a solid historical perspective. This is particularly true in terms of addressing the areas of nationality, identity and ideology. In order to counter this deficiency, it is necessary to consider the development of film music within a historical frame, paying particular attention to cultural factors in further study.

\section{REFERENCES}

[1] Barbash, Ilse and Lucien Taylor, Cross-Cultural Filmmaking: A Handbook for Making Documentary and Ethnographic Films and Videos, Berkeley: University of California Press, 1997, p. 114

[2] Bazin, Andre, What Is Cinema? Vol. I (trans.) Hugh Gray, Berkeley [1967], University of California Press, 1958, pp. 36, 42, 44-52

[3] Bordwell, David, 'Cinema/Sound' in Rick Altman (ed.) Sound Theory Sound Practice, London: Routledge, 1992

[4] Brown, Royal S., Overtones and Undertones: Reading Film Music, Berkeley: University of California Press, 1994, pp.19-20, 27

[5] Eisenstein, Sergei M. and Jay Leyda , The Film Sense, Newyork: Harcourt Brace \& Company, 1947, p.23

[6] Evans, Mark, Soundtrack: The Music of the Movies, New York: Hopkinson and Blake, 1975

[7] Godzich, Wlad, The Cultural of Literacy Cambridge, Mass.: Harvad University Press, 1994, p.79

[8] Gorbman, Claudia, Unheard Melodies: Narrative Film Music, Blooming: Indiana University Press; London: British Film Institute, 1987, pp.14-16, 24

[9] Gray, Hugh (trans.), Andre Bazin: What Is Cinema? 1958: Vol I, Berkeley: University of California Press, 1967, pp. 224-225

[10] Kalinak, Kathryn, 'The Language of Music: A Brief Analysis of Vertigo', in Key Dickinson (ed.) Movie Music the Film Reader, London and New York: Routledge, 2003, pp. 21-22

[11] Kaplan, E. Ann, 'Melodrama, Subjectivity/Ideology: Western Melodrama Themes and their Relevance to Recent Chinese Cinema', in Wimal Dissanayake (ed.) Melodrama and Asian Cinema, Cambridge and New York: Cambridge University Press, 1993

[12] Karlin, Fred and Rayburn Wright, On the Track: A Guide to Contemporary Film Scoring, New York: Schirmer Books, 1990, p, 127

[13] Katz, Ephrain, The International Film Encyclopedia, London: Macmillan, 1979

[14] Prendergast, Roy M., 'The Aesthetics of Film Music' in A Neglected Art: A Critical Study of Music in Film, New York: Norton, New York University Press, 1992, pp. 235-237

[15] Silbergeld, Jerome, China into Film Frames of Reference in Contemporary Chinese Cinema, London: Reaktion Books Ltd., 1999

[16] Willemen, Paul, 'The Zoom in Popular Cinema: A Question of Performance', Inter-Asia Cultural Studies, NC-JCF (1) Intellect Ltd., 2002, pp.6, 10-11 